\title{
Líneas de la increencia en España
}

\author{
Por Javier Martínez Cortés*
}

\section{[ADVERTENCIA]}

La religiosidad (y por tanto la irreligiosidad) constituye un fenómeno complejo y multifacético, no fácil de analizar, especialmente por métodos cuantitativos. Los comportamientos religiosos (o su ausencia), al menos en sus aspectos rituales, son relativamente sencillos de medir. Pero todo análisis sociológico razonable de una situación religiosa deberá prestar atención no sólo a la dimensión externa del fenómeno (comportamiento), sino también a sus dimensiones internas (creencias, sentimientos, actitudes); que ya son mucho más difíciles de captar por procedimientos cuantitativos y encuestas de opinión. Ante la dificultad, es fácil experimentar la tentación de suponer los sentimientos (e incluso las creencias) a partir de los comportamientos. $\mathrm{O}$ a la inversa, deducir la ausencia de sentimientos religiosos, o de creencias, a partir de las deficiencias observadas en la práctica religiosa ritual.

Una segunda advertencia, ya a propósito de los estudios cuantitativos de que disponemos en España. Suelen carecer de continuidad, lo que reduce fuertemente su carácter acumulativo y complementario. $O$ bien la realidad a estudiar es conceptualizada de modo diferente en los distintos estudios; o bien incluso partiendo de una conceptualización similar, se diseñan indicadores distintos, y por tanto, no comparables.

No obstante estas dificultades, creemos que es posible dibujar unos perfiles de por dónde se orienta hoy el fenómeno de la increencia en España.

\section{1.-Las encuestas}

Según las encuestas relativamente recientes (Metra-Seis, 1979, y datos aceptados por el IV Informe Foessa, 1983) a la hora de autodefinirse religiosamente, los españoles, en una sustancial mayoría se consideran católicos. $179 \%$ en el sondeo Metra-Seis, y $77,8 \%$ en los datos de Foessa; el porcentaje sube al $90 \%$ en el estudio de F. Andrés Orizo). En estos porcentajes se comprenden las categorías de católico practicante,

(*) Del Instituto "Fe y Seculazidad". 
poco practicante y no practicante. Se supondría, pues, como base común la adhesión al núcleo sustancial de las doctrinas católicas. Pero a juzgar por la respuesta a otros ítems de las encuestas, hay que ejercer una cierta cautela ante tal autocalificación, que puede tener un carácter de herencia cultural. Porque otros porcentajes de adhesión a dogmas centrales del cristianismo son más bajos, o están afectados de un coeficiente de duda (que habría que interpretar), o no son coherentes entre si. (Es difícil otorgar el calificativo de católico a quien no acepta la divinidad de Cristo, o a un Dios remunerador, o algún tipo de pervivencia más allá de la muerte.)

La creencia en Dios, planteada a este nivel de abstracción, encuentra la aceptación de una notable mayoría. Los porcentajes suelen oscilar en torno al $87 \%$. Lo que indicaría un fondo sustancial de religiosidad en nuestro pueblo. La duda que surge es la de si esta religiosidad (superior a la medida europea, un $75 \%$ ), aunque sea de proveniencia católica -por su educación - se puede llamar hoy ya plenamente católica. Pues si la pregunta se plantea a niveles más concretos, por ejemplo, la afirmación sin dudas de un Dios Creador del mundo, sólo la aceptan un $61,5 \%$ de los respondentes. Con dudas, un 20\%. (Encuesta CIS, enero 1984). La divinidad de Cristo es aceptada totalmente por un $59 \%$. Con dudas, otro $20 \%$. La resurrección de los muertos es aceptada por un $43,2 \%$. Dudan un $21 \%$. La existencia del cielo es afirmada por un $52,6 \%$. Con dudas un $21 \%$.

Si arriesgamos una interpretación de estas cifras, cuya enumeración no parece necesario continuar, diríamos lo siguiente:

- La primera impresión es que no existe una conciencia clara de lo que significa, en el terreno de las creencias, el definirse como "católico" o simplemente "cristiano".

- La doctrina católica, como un "corpus" articulado de creencias, parece encontrarse en un proceso de pérdida de su carácter sistemático. Espontáneamente viene a la cabeza el modelo de "mercado" (sugerido por Luckmann y por Bergel; aplicado a la cosmovisión religiosa: el "cliente" religioso elige (cree) lo que más le gusta, practicando un cierto sincretismo.

- La impresión anterior debería ser corregida en este sentido: el cliente religioso no elige propiamente lo que más le gusta, sino lo que le parece más plausible (creíble) según su nivel cultural y de formación religiosa.

- Esta plausibilidad de unas creencias, e implausibilidad de otras (igualmente centrales en la cosmovisión cristiana) remite a su vez a defectos en la socialización religiosa, que ahora salen a la luz.

- Lo anterior no implica, probablemente, una caída sustancial de "tasas de fe" anteriormente viva. Sino la extinción progresiva, y ya manifiesta, de la simple remisión global a "la doctrina de la lglesia" en cuanto al contenido de la fe. Y la puesta en marcha de un proceso cultural diferente. Muchos de los que se autodefinen 
católicos parecen (debido posiblemente al aumento del nivel general de educación) querer construir, a veces por un procedimiento de cuasi-bricolage, su propia cosmovisión religiosa. $Y$ ello sin grandes preocupaciones de coherencia, sin grandes angustias (se ha desdramatizado el problema de la fe). y sin un sincero interés por informarse acerca de los fundamentos intelectuales de la tradición religiosa en la que ha sido educado (y educado sin grandes pretensiones intelectuales: "fe del carbonero", que muestra ahora su efecto boomerang).

- Este fenómeno es un proceso en marcha; es decir, hoy al menos, está cotado de fuerza expansiva. Su efecto es la constitución de una zona de sincretismo en las creencias, ambigua por su mismo carácter. No se puede situar en la zona del ateísmo convencido, ni militante; ni siquiera del agnosticismo, puesto que hay creencias. Pero tampoco es lícito afiliarla sin problemas a la creencia católica, ya que a veces son negados puntos sustanciales.

- ¿Cuáles serían las perspectivas de evolución del proceso? Parece difícil hacer pronósticos. En gran parte estarán condicionados por la evolución de una variable de suma importancia: el esfuerzo intelectual, dialogante con la cultura contemporánea, de la Iglesia Católica en España, por un lado. Y por otro, de una mejora sustancial de los procesos de socialización religiosa (de la catequesis y su ulterior desarrollo en catecumenado de adultos) por parte de las instancias de base (iniciativa que ya es palpable en el ámbito de la Iglesia española).

\section{2.-Indicadores del futuro}

Como indicadores del futuro se podrían citar datos provenientes de las Encuestas de la Juventud (promovidas por el Ministerio de Cultura). Muestran una doble vertiente. Por una parte tienden a confirmar el fenómeno de la difusión y consolidación de una subcultura que podríamos denominar "secularista" (no simplemente secular o laica), en la que Dios no aparece ni como horizonte de referencia cultural. Viene a agrupar a un $17 \%$ de la población juvenil encuestada (según la Quinta Encuesta de la juventud, 1982). Tal subcultura, hace dos décadas (en 1960) prácticamente no existía. Adscribimos a ella a todos los jóvenes de ambos sexos. en edades comprendidas entre los 15 y los 20 años, que se autodefinen como "no creyentes" o "indiferentes" . Por otra parte, existe una subcultura juvenil católica, claramente mayoritaria, integrada por un $34 \%$ de la población juvenil encuestada, que se autodefine como "católicos practicantes". (El calificativo de "practicante" parece garantizar un mínimo de coherencia doctrinal.) Pues bien, esta subcultura católica presenta ras* gos que la diferencian como tal de la subcultura juvenil secularista. (Se puede hablar, por tanto, de dos subculturas juveniles.) Su integración social parece sermás armónica. Así el 24 por ciento de los católicos practicantes se definen como "muy felices" (frente al $12 \%$ de los "secularistas"). Sólo el $9 \%$ de los católicos dice ser "poco o nada felices" (frente al $22 \%$ de los "secularistas"). Los católicos enfocan también su vida futura 
con algún mayor optimismo que los secularistas; espera que les vaya bien o muy bien un $58 \%$ de los católicos, frente a un $47 \%$ de los no creyentes y un $51 \%$ de los indiferentes. En cuanto a la calidad de sus relaciones familiares, el $43 \%$ de los católicos dice estar muy unido a su familia (entre los no creyentes, solo el 17\%); define sus relaciones como frías y distantes el $4 \%$ de los católicos (porcentaje que se eleva a $27 \%$ entre los no creyentes, y a $16 \%$ entre los indiferentes). También el grado de confianza interpersonal de los católicos es significativamente superior al de los jóvenes secularistas. El $47 \%$ de los primeros piensa que, "en nuestro país, por lo general se puede confiar en la mayor parte de la gente". Entre los no creyentes, sólo el $31 \%$, y entre los indiferentes el $30 \%$, estaría de acuerdo con la frase.

Igualmente la postura ante el matrimonio como institución es positiva en lo sustancial entre tres de cada cuatro jóvenes católicos practicantes; mientras en los no creyentes la proporción es uno de cada tres. Respecto a posiciones sociopolíticas, pese a un desinterés generalizado por estrictos temas políticos, la subcultura católica aparece ideológicamente como más conservadora que la secularista. Puesta a elegir entre términos antitéticos, muestra una clara mayoría en favor de términos tales como "propiedad privada", "monarquía", "no marxismo".

En resumen, se puede establecer una significativa divergencia de opiniones y actitudes entre jóvenes católico-practicantes y jóvenes indiferentes y no creyentes. La subcultura católica aparece, en su conjunto, como más capaz de integrar a los jóvenes en la sociedad actual española (respondiendo así a un clásico esquema durkheimiano de la religión como factor integrativo). Tal proclividad a la integración podría también mostrar sus facetas problemáticas a largo plazo, en cuanto que los jóvenes más dinámicos, o dotados de un espíritu utópico contestatario, se sintieran sistemáticamente excluidos de la subcultura católica. Pero lo que en todo caso habría que hacer notar, frente a ciertas tesis extremadas de la secularización de las sociedades modernas, es la influencia indudable del factor religioso en la configuración de actitudes sociales. La investigación empírica no confirma en modo alguno que la religión sea un factor marginal.

\section{3.- Subcultura católica y subcultura secularista}

Entre la subcultura juvenil católica y la secularista, aparece el grupo juvenil más numeroso: el de los jóvenes autodefinidos como "católicos no practicantes", un $45 \%$. Socialmente, por el solo hecho de su existencia, parecen contribuir a amortiguar los posibles conflictos entre las dos subculturas (católica y secularista) mencionadas. Su magnitud notable sugiere la difusión de un proceso de "desenganche" de la Iglesia Católica ( $y$ a constatable en menor grado entre la población adulta).

Esta "no práctica" de un tan numeroso grupo juvenil (de modo semejante a las "dudas" encontradas en la creencia de los adultos) plantea problemas de interpretación, difícilmente solubles por métodos cuantitativos; lejos de constituir un mero problema académico, presenta profundas repercusiones en el terreno de la pastoral de la Iglesia. Las 
"dudas" de los adultos, ¿son expresión de un proceso de interiorización y maduración de una fe personal? ¿O son más bien una etapa en el camino hacia la increencia católica? De manera similar, la no-práctica católica de los jóvenes, Les un mero período transitorio de rebeldía adolescente frente a preceptos eclesiales? ¿O más bien un paso en el alejamiento progresivo de las creencias recibidas, y se orienta hacia la subcultura secularista? Preguntados sobre el grado de su creencia en Dios, los jóvenes católicos no practicantes afirman su creencia, pero con porcentajes de vacilación superiores a los practicantes. De los no-practicantes, un $36 \%$ cree firmemente; un $45 \%$ más bien cree; un $15 \%$ duda; un $2 \%$ más bien no cree, y un $1 \%$ no cree en absoluto. La creencia, pues, es afirmada; pero se manifiesta ya más claramente una orientación hacia la duda (incluso con un planteamiento tan genérico, como es la creencia en Dios, sin más especificaciones cristianas). La tendencia existe, aunque se manifieste muy paulatinamente; (los datos que pretenden probar transformaciones sociológicas espectaculares, o no son fiables, o están mal interpretados). $Y$ tiene lugar mediante un alejamiento de la práctica católica, es deçir, del área de influencia de la Iglesia. Area que tiende a reducirse. La consolidación de una "subcultura secularista juvenil" (aunque minoritaria) apunta en idéntico sentido.

Todo ello remite a cuestiones de socialización católica en las condiciones propias de los procesos de modernización por los que atraviesa la sociedad española. Se está constituyendo una sociedad civil pluralista. Es decir, una sociedad en la que las ofertas de identidad pueden ser múltiples: religiosas y no religiosas. Con su sola existencia, ofrecen alternativas sociales plausibles al modo de existencia católico. Si éste no se halla convincentemente interiorizado, la posible rebeldía, o simple desafección juvenil, encuentra un punto de apoyo social para consolidar posturas alejadas de su originaria educación católica. No porque opten explícitamente por otra cosmovisión religiosa (los porcentajes son minimos: $2 \%$ en la encuesta de 1977; $1 \%$ en la de 1982). Ni tampoco porque formulen un ateísmo explícito (5\% en 1982, inferior al porcentaje de 1977, que dio un $8 \%$ ). Sino porque la "oferta de identidad" católica, al no resultarles atractiva, les impulsa hacia búsquedas de identidad diversas, que en lo religioso desembocan o bien en la indiferencia, o bien en la nopráctica católica.

Es significativo - creemos-el hecho de que los porcentajes juveniles de los que se autocalifican de indiferentes tienden a disminuir en 1982 (un $11,7 \%$, frente a un $19.7 \%$ en 1975 y un $21 \%$ en 1977 ). El problema del sentido parece volver a plantearse, y la mera indiferencia no es socialmente satisfactoria (puesto que disminuye). ¿Consecuencia, en parte al menos, de la crisis económica y de modelo de civilización, que enfrenta el Occidente?

En cambio crece de manera notable el número de los jóvenes que, confesándose católicos, declaran no ser practicantes (aunque la categoría de "no practicante" es ambigua, al menos en su determinación subjetiva. Hay correlaciones que muestran que los no-practicantes practican al menos esporádicamente: van ocasionalmente a Misa, o celebran matrimonio católico - lo que puede explicarse por presión social-). Católi- 
cos no-practicantes se declaraban en 1960 un $7,7 \%$; en 1975 un $18,3 \%$; en 1977 , un $23 \%$; en 1982 son ya el $45 \%$ (Informe Sociológico sobre la Juventud Española. Fundación Santa María. Madrid, 1984). El porcentaje se ha multiplicado por seis. Duplica al porcentaje de población adulta que también en 1982 se confesaba católica no practicante: un $21,8 \%$ (IV Informe Foessa. 1983). Los indicios, son, pues, los de una tendencia en expansión.

En la base de esta desafección creciente de los jóvenes por la práctica católica no parece estar una experiencia negativa (puesto que los rasgos de la subcultura católica juvenil manifestaban una más satisfactoria integración: de la personalidad propia y con la sociedad circundante). $\mathrm{Ni}$ una dificultad de raíz intelectual, como pudiera ser el predominio generalizado de una mentalidad empirista (puede hallarse algún indicio, pero lo estimamos minoritario. En la mentalidad juvenil -y también en séctores de adultos - coexiste con frecuencia una curiosa mezcla de cierto cientifismo, o mejor "tecnologismo", con una amplia aceptación de lo mágico: no se rechaza por tanto lo sobrenatural por no-racional). De hecho, de los jóvenes que se declaran no-practicantes, un 35\% dice creer firmemente en Dios; incluyendo a los que "más bien creen" y a los que dudan, el porcentaje se eleva a un 95\%. (Juventud española 1960-1982. Informe de la Fundación Santa María.)

A título de hipótesis (no investigada) podríamos sugerir problemas de imagen (de la Iglesia) y tal vez de lenguaje. El área juvenil desafecta a la Iglesia parece estar dotada de un determinado tipo de sensibilidad: privatista, libertaria, con cierta ansia de experimentación, oscilante entre los reclamos del marketing publicitario y una necesidad de comunicación no siempre satisfecha; consciente de que constituye un grupo social "diferente" de los adultos, pero palpando su impotencia para modificar el mundo adulto. Roto su contacto con la Iglesia en sus formas concretas (parroquias, catecumenados, comunidades eclesiales), este sector juvenil mantiene un estereotipo de Iglesia que, a juzgar por los efectos, presenta rasgos negativos que se estiman difícilmente compatibles con su existencia cotidiana. Es éste un punto -el de las motivaciones de la desafección juvenil por la Iglesia en tan amplio sector-que estimamos merecería ser cuidadosamente investigado. Parece, además, ser un fenómeno común a las diversas sociedades modernas europeas, que en España aún no habria encontrado su "techo".

\section{4.-Posibles raíces de la increencia en España}

A la hora de indicar las posibles raices de la increencia en España, nos encontramos conque de las señaladas por el Concilio Vaticano II al hablar del ateísmo - mentalidad empirista, concepciones humanistas ateas, ateísmo político, actitudes meramente pragmatistas-, ninguna de ellas goza de una amplia tradición en la cultura española. En efecto, la mentalidad empirista (debido posiblemente a la hasta tiempos recientes escasa difusión de los niveles educativos) ha sido más bien patrimonio de minorías. Sólo ahora, cuando los presupuestos empírico-positivistas son puestos en cuestión por los propios científicos, es cuando la mentali- 
dad empirista alcanza una cierta difusión en ámbitos de la educación superior, por un efecto de inercia cultural. Pero ya hemos indicado al hablar de la juventud cómo en ésta parece coexistir, junto a un tipo de actitud cientifista, una aceptación de lo "extraño" y no racionalísticamente explicable. La mentalidad empirista, como obstáculo para la fe, parece seguir siendo aún patrimonio de minorias, aunque más extendidas.

Los humanismos ateos, explícitamente formulados, tampoco constituyen una poderosa corriente cultural española (como fue el ateísmo existencialista en Francia). Ni Prometeo, ni Sísifo son mitos masivamente orientados para los españoles. Recientemente se ha formulado en nuestro ambiente cultural una llamada a un humanismo "religiosopoliteísta". Se trataría de una exaltación de la vida en su finitud, de los valores múltiples y parciales, no reductibles a síntesis totalizantes /de ahi el "politeismo"). Frente a la mentalidad cientista, se hace profesión de un retorno a "lo religioso": pero una religiosidad libre de dogmas, negadora del Dios del monoteísmo (porque en cualquier pretensión de monoteísmo - es decir, de predominio de un sentido de la vida- acecharía la tentación del totalitarismo). En realidad se trata de una postura vitalista, que creemos puede dar expresión de un difuso sentimiento de amplias zonas de juventud (aunque ésta ignora sus formulaciones). Pero más bien traduce que produce esas actitudes vitales: no se puede hablar, pues, de un influjo intelectual.

En cuanto a los ateísmos políticos, el marxismo como cosmovisión sistemática, parece hallarse en España en un notable proceso de desarticulación. No hay datos explícitos, aparte de una cierta correlación general entre menores tasas de práctica religiosa y de creencia, y posiciones políticas de extrema izquierda. Sin embargo, hoy la identificación izquierda = increencia parece parcialmente rota en España. Los indicios son de que, incluso en el plano de la afiliación política, el marxismo como cosmovisión no supone un horizonte mayoritariamente atractivo, aunque se acepten sus tesis económicas.

Quedaría el "ateísmo pragmático" o indiferentismo. En la circunstancia española, habría que concebirlo como un proceso de progresiva extinción de significado de los elementos católicos recibidos en la educación. (En el IV Informe Foessa, manejando datos de 1982, se afirma que el $95 \%$ de la población española ha recibido el bautismo.) En el mismo informe, el porcentaje de los que se autocalifican de indiferentes es de un $11,5 \%$. Supone un crecimiento, si se compara con la fecha de 1965 (primer año para el que disponemos de cifras sobre este tema. Banco de datos del $\mathrm{CIS}$ ). Entonces se apuntaba un exiguo $2 \%$, que englobaba las autocalificaciones de "indiferente" y de "no creyente". Si de la población adulta pasamos a los jóvenes, el primer dato proviene de 1975 (Tercera Encuesta de la Juventud): el porcentaje de "indiferentes" es significativamente más alto: un 19,7\%. Que aún se eleva al $21 \%$ en 1977 (Cuarta Encuesta de la Juventud). Pero en 1982 (Quinta encuesta) sufre una drástica inflexión: el $11.7 \%$. Prácticamente el mismo que el de la población adulta. (En cambio, según ya mencionamos, el de los jóvenes católicos no practicantes sigue su "crescendo": un 45\%). Los que se declaran explícitamente ateos no pasan del 3,1\%. La no creencia y la indi- 
ferencia, como actitudes vitales extendidas, aunque muestran una tendencia al crecimiento, no dan señales de una masiva aceptación.

Si las consideraciones anteriores (incluso contando con la imprecisión de los datos) dibujaran un perfil fundamentalmente correcto, nos encontraríamos conque el problema mayor que enfrenta la fe cristiana, en nuestro país, es la relación entre el creyente no practicante y la Iglesia (manifestado con especial relieve en el área juvenil). Problema que afecta a la fe. Porque la Iglesia es la que se constituye en garante de la coherencia y la integridad de la fe, y de su expresión en la práctica. Esta práctica es la que va siendo abandonada; y ello parece significar el primer paso en la constitución de una zona social de increencia difusa.

En 1965 , el $83 \%$ de la población adulta española se definía como "católico practicante", y el 15\% como "católico no practicante". En 1982 , los católicos practicantes han descendido al $50 \%$ y los no practicantes dan un porcentaje del $38 \%$. (Banco de datos del CIS). Parece altamente problemático, por tanto, interpretar el alejamiento de la práctica religiosa como etapa meramente transitoria de la biografía individual, incluso entre los jóvenes, entre los que la curva de no-práctica religiosa experimenta un ascenso acelerado.

Y si este alejamiento de la Iglesia no parece encontrar raíces intelectuales en la cultura española, habrá que buscar sus motivaciones en otras áreas más vitalistas: la de los valores.

\section{5.-El cambio de los valores}

En el tema de los valores no deberiamos esperar, a priori, cambios espectaculares. Ya hemos insinuado antes un escepticismo sobre las "transformaciones sociológicas" sensacionalistas. Se tiende siempre a minusvalorar el peso de las inercias y los hábitos adquiridos. Pero ello no significa que no se den tendencias al cambio, y que no sean identificables algunos de los factores que las aceleran o que las frenan. La evolución social no es fatalista, $y$ existen agentes sociales.

El informe sobre el cambio de valores en la Europa Occidental, promovido por el European Value System Study Group (EVSSG) parece confirmar lo antedicho. (Cfr. Stoetzel, Jean: Qué piensan los europeos. Madrid, 1983). La impresión que vehicula en su conjunto es que "las opciones religiosas, políticas, morales, profesionales, familiares, forman lazos complejos" que no se alteran con rapidez. Así, planteada la opción entre 17 actitudes, de las que ocho se consideraban como pertenecientes al grupo de las "tradicionales" $y$ nueve al grupo de las "innovadoras, un $52 \%$ de los europeos encuestados se inclinaba por actitudes tradicionales y un $48 \%$ por actitudes innovadoras. Por tanto, continuidad y cambio, sin rupturas espectaculares. Pero cambio.

Este cambio, en las sociedades modernas, parece darse de modo más acelerado en la esfera de lo cultural, debido a la compleja red de comunicaciones sociales. Y las generaciones más jóvenes son especialmente sensibles a él, hasta el punto de constituir subculturas juveniles 
específicas, encajadas en el marco más amplio de la cultura nacional. En el tema del cambio podríamos distinguir entre "zonas duras" (el entramado político-económico, donde el influjo juvenil es muy reducido) y "zonas blandas" (el área cultural, y también religiosa) donde las posibilidades de hacer "opciones individuales" respecto a la configuración de sus costumbres y a la aceptación o rechazo de la religión, está mucho más al alcance de los jóvenes - aunque a veces sea instrumentalizado por la sociedad adulta: el fenómeno del consumo juvenil.

España - que figura entre los países encuestados en el anterior informe del EVSSG (véase, España entre la apatía y el cambio social, de F. A. Orizo. Madrid, 1984) - muestra, en lo que se refiere al cambio de los valores, un perfil similar al de otras naciones europeas: se produce el cambio, pero dentro de una continuidad con los valores tradicionales. Sin embargo, esta semejanza con el área europea supone respecto al propio país una serie de alteraciones mucho mayores, constatables con sólo echar una ojeada a los acontecimientos de las dos últimas décadas. De una sociedad tradicional, agraria y autoritaria hemos pasado a una sociedad industrial, urbana, y por último democrática. No sólo han evolucionado nuestros "perfiles blandos" (culturales) sino nuestros perfiles "duros" (estructuras económicas y políticas). Es decir, nos hemos incorporado a ese conjunto de fenómenos sociales que se suele designar como "modernidad" (y ya se empieza a hablar de "postmodernidad"). Tal cambio tiene que comportar, forzosamente, consecuencias en la configuración y en la vivencia de lo religioso.

Ha variado la posición estructural de la Iglesia Católica en el entramado constitucional del Estado español, ahora oficialmente laico. Sociológicamente hace su aparición legitimada el fenómeno cultural del pluralismo. Se constituye una sociedad civil laica. Ello supone el relegar oficialmente a un segundo plano toda moral unitaria con pretensiones universales, soberanas y dogmáticas. En su lugar aparece un conjunto de valores relativamente "nuevos" en nuestras circunstancias: los valores cívicos. Valores poco grandilocuentes y sin pretensiones sobrenaturales: son virtudes para la convivencia cotidiana. Pese a fenómenos sociales espectaculares (y de indudable importancia) como la droga y la delincuencia juvenil, la sustancial mayoría de nuestras generaciones jovenes asimilan, al menos en su versión dentro de la subcultura juvenil, estos valores de convivencia. Con ellos intentan configurar una existencia social que, al menos hoy - véanse las estadísticas de paro juvenil-, no se presenta muy halagüeña. Si nos atenemos a un estudio cualitativo realizado en el Instituto Fe y Secularidad para el Ministerio de Cultura, los jóvenes en su conjunto valoran a una serie de elementos "tradicionales" (la honradez, la sinceridad). Pero a su lado aparecen otros que pudiéramos considerar "innovadores": la capacidad para la confraternización instantánea; una cierta concepción de la autenticidad -que los adultos tenderíamos a calificar de espontaneidad-; una idea de libertad bastante radicalizada, al menos en sus expresiones verbales; la naturalidad de lo corporal en sus mutuas aproximaciones; la variedad o versatilidad en sus maneras de ser - ireflejo adquirido del pluralismo social?-; la reivindicación del derecho a modelar sus vidas según sus propios criterios; el diálogo en un nivel de igualdad. 
Ante el esquema de personalidad social que tales rasgos dibujan, surge la sospecha (a falta de investigaciones sobre el tema) de que la imagen recibida de la institución religiosa, no concretada en ulteriores contactos y experiencias, se limita a un estereotipo que se juzga incompatible con las aspiraciones vitales cotidianas. ¿Puede ser ésta una de las causas de su alejamiento de la práctica religiosa? (que se aproxima al $50 \%)$.

Otro punto, que nos parece importante $-y$ que sólo podemos mencionar-, deriva de lo que podríamos llamar "constitución gremial" de la sociedad civil moderna. Con esta expresión queremos aludir al hecho de que, pese a sus ideologías igualitarias, los países modernos, técnicamente avanzados y políticamente enmarcados en el orden de las democracias pluralistas, se están reestructurando según nuevos criterios de poder, privilegio y moralidad. La contemplación de las fases más recientes de su evolución invita a que (sin tomar la expresión en sentido muy estricto) las entendamos como "sociedades corporativas". En ellas, la atribución de poder; recursos, desigualdad y privilegios, se realiza sobre todo a través de corporaciones (un mosaico social más complejo que el de las clases en sociedades menos desarrolladas, aunque éstas - las clases - también existan). Las sociedades liberales sufren vastos procesos de burocratización, sindicación, y en general de organización corporativa de intereses sectoriales. Estos intereses organizados entran en conflicto, $y$ "producen" la realidad social mediante pactos entre empresas, sindicatos, partidos, organismos estatales, etcétera. La "ética" de semejante sociedad sería una ética de compromisos decentes y contratos razonables y pragmáticos. En semejante jungla corporativa de una sociedad laica, existe el peligro de que la Iglesia aparezca como una organización corporativa más, que defendería sus propios intereses sectoriales, con una moralidad igualmente sectorial. Los jóvenes como grupo social, conscientes de su "diferencia", pero con escasa fuerza para intervenir en el juego de pactos, se sentirían frustrados, y lógicamente, en un mundo orientado por el "colectivismo particularista" (Salvador Giner), no estarían propensos a dejar orientar sus vidas - de momento, su más preciada propiedad - por una de estas "morales particulares" (la de la Iglesia Católica). El tema (que no es sino otro aspecto del anterior) está igualmente por investigar.

Por último, también nos parece digno de ser apuntado uno de los factores más individualizados que están en la base de la evolución global de la juventud respecto a la Iglesia; la subida en el nivel educativo de la mujer, que propicia actitudes de emancipación femenina, ante las que la Iglesia no parece tomar partido. El tema, en su globalidad, es serio, porque - al menos en España - la mujer en la familia ha sido uno de los pilares de la socialización religiosa. Un alejamiento sustancial en la práctica religiosa de parte de la juventud femenina supone también un debilitamiento correspondiente en la interiorización de la fe en los primeros años de vida de la generación siguiente. Los Informes sobre la Juventud del Ministerio de Cultura muestran siempre, en lo referente a la autocalificación religiosa de los jóvenes, un acusado dimorfismo sexual: son siempre más los varones indiferentes o católicos no practicantes que las mujeres. Pero los porcentajes absolutos de éstas aumentan en cada encuesta. 
Con una excepción: en lo que se refiere a la autodefinición de "indiferente", el porcentaje cae de modo notable si se compara 1982 (un $9,4 \%$ de las mujeres) con 1977 (un 17\%) e incluso 1975 (un 13,6\%). Pero lo mismo sucede con los varones. En cambio, la autocalificación de nopracticante sigue su ritmo ascendente (lo mismo que en los varones): un $13.4 \%$ de las mujeres en 1975 (en 1960 eran tan sólo el 1.6\%); un 19\% en 1977; que sube al $39,8 \%$ en 1982 .

El fenómeno nos parece digno de ser notado. Y sus causas, investigadas. Porque en ellas reside un elemento importante de la evolución de la fe - al menos de la fe transmitida en los primeros años de socialización en la sociedad española de mañana-. Esto es, en sustancia, lo que tendríamos que sugerir sobre los perfiles de la increencia en España. Sobre un fondo masivamente religioso, y con unos números abolutos notables de práctica religiosa (de nueve a diez millones asisten a la misa dominical, sin contabilizar la población menor de 18 años, según las observaciones hechas por F. Azcona al estudio del CIS), se dibujan sin embargo algunos problemas de importancia. Una falta de articulación entre creencias fundamentales en el catolicismo, que son aceptadas o rechazadas según criterios estrictamente particulares. $Y$ entre la juventud (como indicador de un futuro probable), un alejamiento de la práctica religiosa, cuyos porcentajes tienden a crecer entre ambos sexos; alejamiento que más que deberse a causas estrictamente intelectuales ("dificultades en la fe"), parece proceder de la nueva situación de pluralismo que presenta la imagen de la Iglesia bajo una nueva y difícil luz.

La Iglesia como "signo" que desborda las particularidades corporativas de una sociedad con intereses plurales; la aproximación religiosa a la juventud a través de un diálogo inteligible y de la participación; la socialización en la fe como una experiencia viva, pero dotándola al mismo tiempo de un fuerte trasfondo intelectual: éstas serian (si las apreciaciones anteriores fueran sustancialmente correctas) algunas tareas importantes en una pastoral de la increencia en España.

\section{BIBLIOgRAFIA}

\section{General}

Sondeo sobre la religiosidad de los españoles. Metra-Seis. Madrid. 1979.

IV Informe FOESSA. Vol. 2. Madrid, 1983.

Iglesia, Religión y Politica. Encuesta del CIS en Revista Española de Investigaciones Sociológicas. N. ${ }^{\circ} 27$, julio-septiembre, 1984, pp. 295-328.

Francisco AZCONA SAN MARTIN: La religiosidad de los españoles. En Ecclesia 16-2-1985. N. 2.209, p. 16.

Jean STOETZEL: ¿Qué pensamos los europeos? Encuesta sobre los valores morales, sociales, politicos, educativos y religiosos en: Alemania Federal, Bélgica, Dinamarca, España, Francia, Gran Bretaña, Holanda, Irlanda e ttalia. Mapfre. Madrid, 1983. 
F. Andrés ORIZO: España entre la apatia y el cambio social. Mapfre. Madrid, 1984. (Estudio realizado sobre los datos relativos a España en la encuesta anterior.)

\section{Juventud}

Comisión Episcopal de Pastoral: Juventud, 1975. Informe, (Edición: "ad usum privatum". Del Secretariado Nacional de Catequesis. Madrid, 1975.)

Fundación Santa Maria: Informe sociológico sobre la juventud española, 1960/1982. S. M. Ediciones. Madrid, 1984.

Ministerio de Cultura. (Dirección General de la Juventud): Encuesta de la Juventud 1982. Dirección General de la Juventud. Madrid, 1984.

Instituto Fe y Secularidad: Mores y moral de la juventud hoy en el área urbana madrileña. (Investigación cualitativa realizada para el Ministerio de Cultura.) Madrid, 1982. (No publicado). 